\title{
Hereditary Retinal Dystrophy
}

National Cancer Institute

\section{Source}

National Cancer Institute. Hereditary Retinal Dystrophy. NCI Thesaurus. Code C35194.

An inherited form of retinal dystrophy. 